\title{
Mechanical Characterisation of Carbon-Silica Reinforced Composites for Turbine Application
}

\author{
Olatunde Sekunowo ${ }^{1}$, Stephen Durowaye ${ }^{1}$, Oluwabamibo Ogunsina ${ }^{2}$ \\ ${ }^{1}$ Department of Metallurgical and Materials Engineering, University of Lagos, Nigeria \\ ${ }^{2}$ Department of Metallurgical and Materials Engineering, Federal University of Technology, Nigeria \\ Corresponding author: sdurowaye@unilag.edu.ng
}

Received: Sep 24, 2018

Revised: Nov 25, 2018

Accepted: $\operatorname{Dec} 2,2018$

\begin{abstract}
Materials selection and development for application in advanced systems is becoming highly complex involving the need for lower cost alternatives without compromising service performance. This paper investigated selected critical mechanical properties of ceramic matrix composites synthesized from coconut shell carbon (CSC) reinforced with silica particles (SP). Coconut shells (CCS) and silica sand (SS) were pulverized separately in a plate mill and a ball mill respectively to obtain a particle size of $250 \mu \mathrm{m}$. The CCS powders were calcined at $500^{\circ} \mathrm{C}$ in an oven to obtain coconut shell ash (CSA) which was carbonized in a furnace from $500^{\circ} \mathrm{C}-1000^{\circ} \mathrm{C}$ under argon gas controlled environment. The materials were mechanically blended while the SP additions varied from $10-40 \mathrm{wt}$ \% and compacted using hydraulic press. The compacted mixture was sintered at $500^{\circ} \mathrm{C}-1200^{\circ} \mathrm{C}$, held for $2 \mathrm{hrs}$ and the composites characterised for mechanical properties while the microstructural integrity was analysed using scanning electron microscope/energy dispersive x-ray spectroscopy (SEM/EDS). Microstructure showed that after sintering, coconut shell carbon developed strong cohesion with the silica particles which gave rise to effective load transfer. The mechanical properties that ensued demonstrated on the average $52.8 \%$ comparability with conventional power plant structural materials in terms of hardness, compressive strength and impact energy.
\end{abstract}

Keywords: Ceramic matrix composites, microstructure, mechanical properties

\section{Introduction}

One of the factors that impact the efficiency of a power plant is the thermal and mechanical characteristics of critical components of its turbine. Ceramic composites are known to exhibit high thermal characteristics. However, their brittle nature under impact load has been a major concern in application environments where stress is combined with elevated temperature [2,9]. Hence, the imperative to develop ceramic matrix reinforcement that can significantly reduce the composite intrinsic brittleness. Both the choice of reinforcing material suitable for such application and the form in which such material is to be employed, demand scientific investigation in order to proffer an effective remedy.

Generation of agro-waste in most developing countries has greatly increased over the years as a result of increase in population and agricultural activities. The most widely used method of 
managing these agro-wastes is open air burning. Due to the adverse effect associated with open air burning, there is a need to explore other disposal options where agro-wastes can be productively utilized with little or no harmful environmental effects. However, apart from the seemingly pioneering work of Madakson et al. [8] which reported that the carbon in coconut shell ash has the potential utilization as reinforcement in ceramics composites, there is a huge information gap with regard to using agro-waste in ceramic based composites. This has placed a huge limitation on the scientific basis for processing and utilising carbon particles obtained from agro-waste to produce high performance advanced materials with characteristics light weight. The aim of this work is to develop and evaluate the functional mechanical characteristics of coconut shell carbon reinforced ceramic composites for applications as power plant turbine blades and steam buckets. As an organic contaminant, the productive use of coconut shells will help to mitigate the adverse effect on the environment arising from its improper disposal.

\section{Materials and Methods}

\subsection{Materials}

The major materials employed for the study consist of coconut shell (CS), silica sand (SS), sodium bentonite and distilled water.

\subsection{Production of the Composites}

Sufficient quantities of coconuts were obtained from a coconut farm and the shafts removed to isolate the nuts. Then, the edible portion of the nuts was removed with a sharp knife while the CS left was first oven dried and then ground into powder in a ball mill (Figs. 1a and 1b) and calcined into ash at $500^{\circ} \mathrm{C}$ in an oven. The coconut shell ash (CSA) was then carbonized in a furnace at $500^{\circ}$ $\mathrm{C}-1000^{\circ} \mathrm{C}$ under argon gas controlled environment. Fig. 2 shows a typical X-ray Diffractogram (XRD) of carbonized coconut shells obtained under the same conditions employed in this study. The silica sand was first oven dried and then pulverized in a ball mill and sieved to $250 \mu \mathrm{m}$ particle size. Both carbon and silica powders fractions with addition of sufficient amount of distilled water were mechanically mixed with sodium bentonite according to the mix design shown in Table 1. The various mixes were compacted in a cylindrical metal mould using hydraulic press at $30 \mathrm{kgf}$. Prior to a full scale sintering in a furnace, the green compacts were oven dried between $200^{\circ} \mathrm{C}$ and $300^{\circ} \mathrm{C}$ to avoid crack during sintering. The composites were then sintered (Figs. 2a and 2b) by subjecting them to a gradual heating from $500^{\circ} \mathrm{C}-1200^{\circ} \mathrm{C}$, held for $2 \mathrm{hrs}$ and allowed to cool in the furnace.

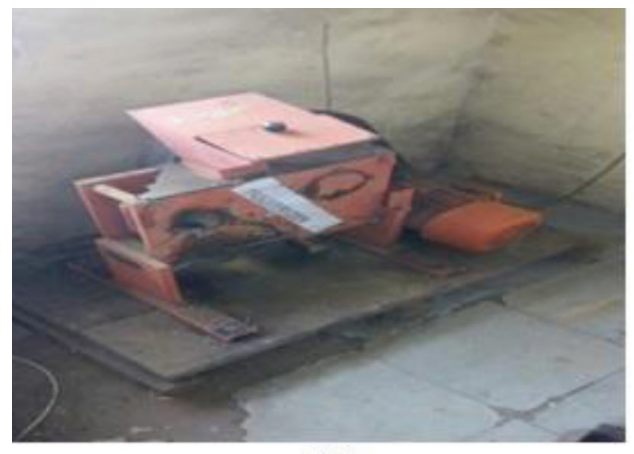

(a)

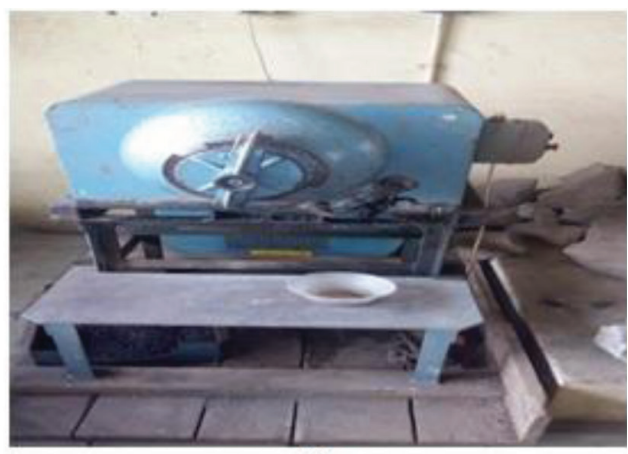

(b)

Fig. 1: (a) Pulverizer (b) Ball mill 


\subsection{Characterisation of the Composite Samples}

The sintered composite samples were characterised for microstructural integrity and mechanical properties using JEOL JSM-5900LV scanning electron microscope (SEM) equipped with an energy dispersive X-ray spectrometer (EDS) facility, Instron universal testing machine, Avery impact tester and Brinell hardness testing machine respectively.

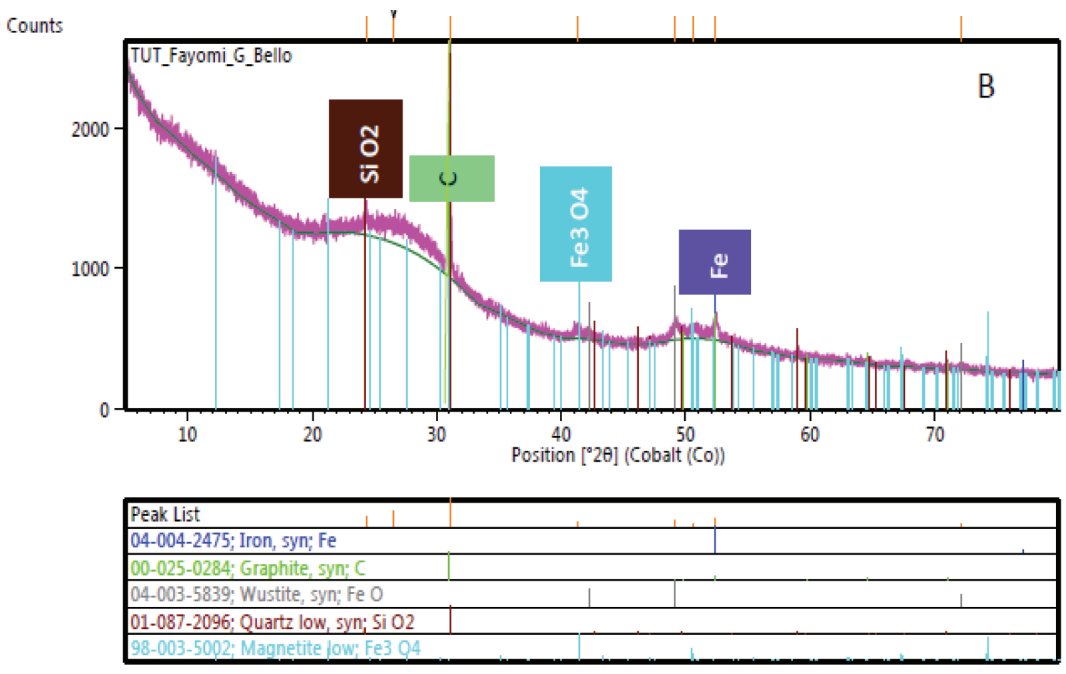

Fig. 2: XRD image of coconut shells [3]

Table 1: Samples formulation

\begin{tabular}{|c|c|c|c|}
\hline \multirow{2}{*}{ Sample } & \multicolumn{3}{|c|}{ Materials (wt. \%) } \\
\cline { 2 - 4 } & Carbon & Silica & Bentonite \\
\hline A & 80 & 0 & 20 \\
\hline B & 70 & 10 & 20 \\
\hline C & 60 & 20 & 20 \\
\hline D & 50 & 30 & 20 \\
\hline E & 40 & 40 & 20 \\
\hline
\end{tabular}

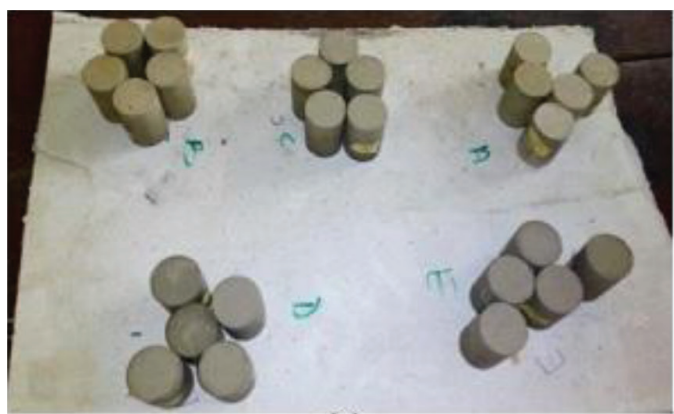

(a)

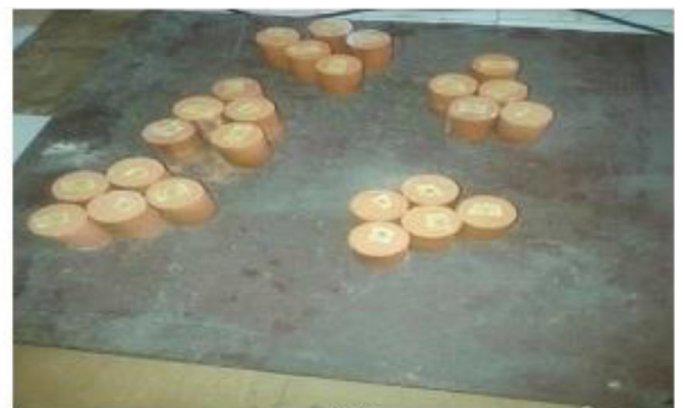

(b)

Fig. 3: Compacted silica reinforced carbon matrix composites (a) Green compacts, (b) Sintered samples 


\section{Results and Discussion}

\subsection{Microstructure}

The SEM micrograph and EDS spectrograph of the $20 \mathrm{wt} . \%$ SP reinforced carbon composite sample, being the composite that demonstrated the best mechanical characteristics are shown in Figs. $4 \mathrm{a}$ and $4 \mathrm{~b}$. It is observed that the silica particles reinforcement phase dispersed homogeneously within the carbon matrix. This actually provided the particles sufficient contact area with the carbon matrix which is relatively soft (graphite formed at the fairly low carbonization temperature of $1200^{\circ} \mathrm{C}$ ). However, because of the traditional strong and directional bonding between carbon atoms and silica particles, limited plasticity is conferred on the composite confirming the report by Ritchie [10], hence the relatively low impact toughness exhibited by the composite. Varied elemental concentrations retained within the composites phases after sintering are presented as obtained by EDS analysis in Tables 2 and 3 at $20 \mathrm{wt} . \%$ and $40 \mathrm{wt} . \%$ respectively. The structure developed at 40 wt. \% SP addition (Fig. 4a) revealed two features namely: inhomogeneous particles dispersion and an extensive particle coarsening resulting in a relatively large particle size. This type of microstructural feature is known to impair desirable mechanical properties such as toughness (impact energy), modulus and shear strength because it promotes weak cohesion between the particles and the matrix. Thus, the low mechanical properties exhibited by the composite at $40 \mathrm{wt}$. $\% \mathrm{SP}$ addition is attributable to its poor microstructural integrity.

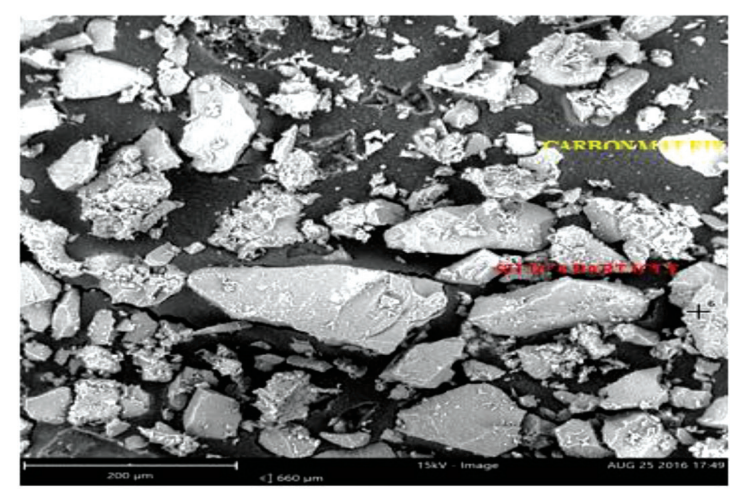

(a)

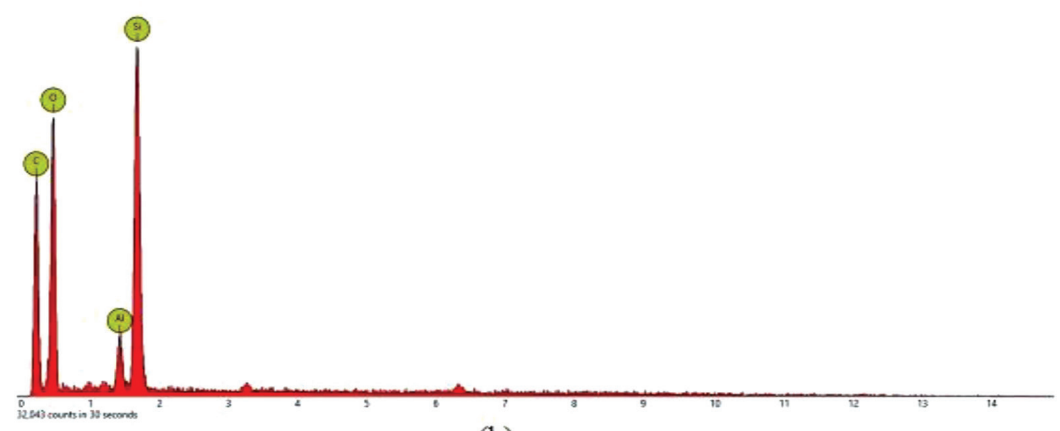

(b)

Fig. 4: (a) SEM micrograph and (b) EDS spectrograph of 20 wt. \% SP reinforced carbon composite with the elemental composition 
Table 2: Elemental composition of the 20 wt. \% SP reinforced carbon composite

\begin{tabular}{lcccc}
\hline Elements & $\begin{array}{c}\text { Oxygen } \\
(\mathrm{O})\end{array}$ & $\begin{array}{c}\text { Silicon } \\
(\mathrm{Si})\end{array}$ & $\begin{array}{c}\text { Aluminium } \\
(\mathrm{Al})\end{array}$ & $\begin{array}{c}\text { Carbon } \\
(\mathrm{C})\end{array}$ \\
\hline Concentrations & 11.3 & 20.8 & 4.1 & 63.8 \\
\hline
\end{tabular}

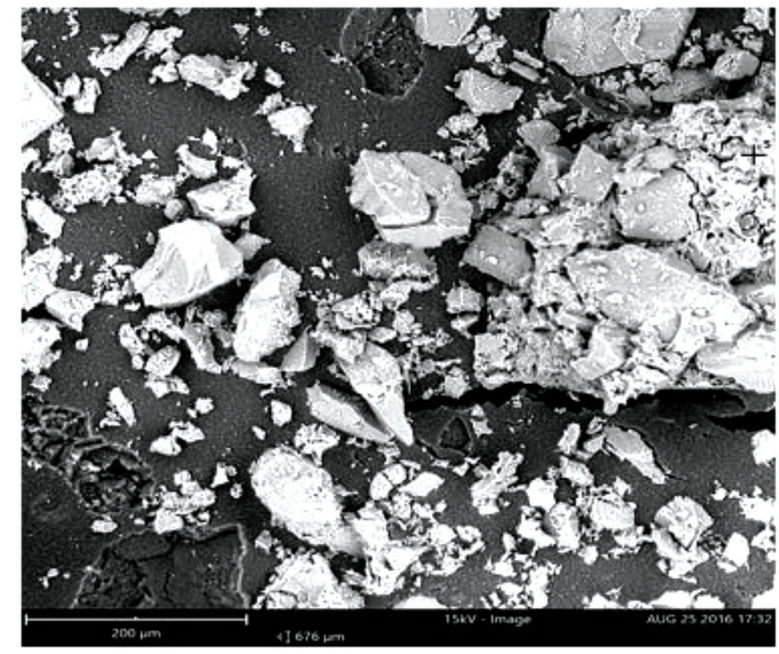

(a)

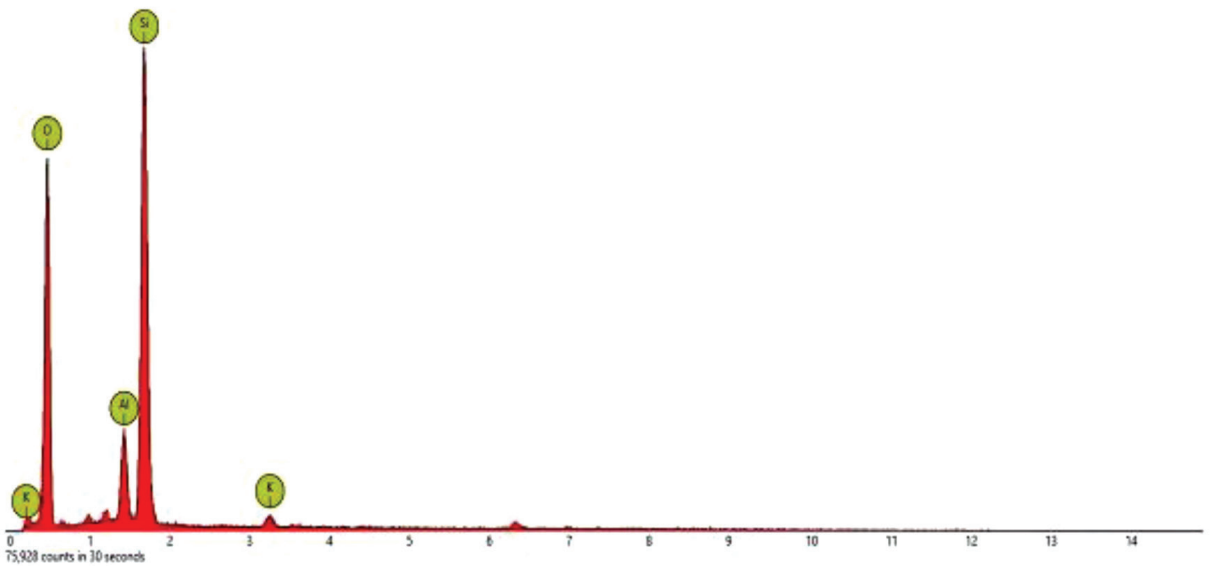

(b)

Fig. 5: (a) SEM micrograph and (b) EDS spectrograph of 40 wt. \% SP reinforced carbon composite with the elemental composition

Table 3: Elemental composition of the 40 wt. \% SP reinforced carbon composite

\begin{tabular}{cccccc}
\hline Elements & $\begin{array}{c}\text { Potassium } \\
(\mathrm{K})\end{array}$ & $\begin{array}{c}\text { Silicon } \\
(\mathrm{Si})\end{array}$ & $\begin{array}{c}\text { Oxygen } \\
(\mathrm{O})\end{array}$ & $\begin{array}{c}\text { Carbon } \\
(\mathrm{C})\end{array}$ & $\begin{array}{c}\text { Aluminium } \\
(\mathrm{Al})\end{array}$ \\
\hline Concentrations & 1.6 & 42.3 & 13.5 & 37.7 & 4.9 \\
\hline
\end{tabular}




\subsection{Compressive Strength}

The maximum load bearing capacity of the composite was determined in a compressive strength test and the results are illustrated in Fig. 6. It is observed that the sample without silica particles (SP) addition has the lowest compressive strength of $115.3 \mathrm{MPa}$ compared with other samples reinforced with varied additions of SP showing compressive strength ranging between 138.3 MPa and $187.8 \mathrm{MPa}$ which compare well with that of conventional martensitic steels used in power plant structural components. The sample with $20 \mathrm{wt}$ \% SP demonstrated the highest compressive strength of $187.8 \mathrm{MPa}$. This behaviour can be explained in term of the extent of wettability provided by the carbon matrix on the SP resulting in effective load transfer. It thus appears that the absence of SP in the control sample invariably gave rise to carbon-carbon interactions that resulted in a relatively low compressive strength. As observed in the current study however, the effectiveness of carbon as a wetting agent in a ceramic system appears to be on the average, in the ratio 8:1 for carbon/silica. This assertion is corroborated by the fact that a decrease in carbon/silica ratio to $4: 1$ gave rise to corresponding decrease of about 15 percent in compressive strength from $162.5 \mathrm{MPa}$ to $138.3 \mathrm{MPa}$.

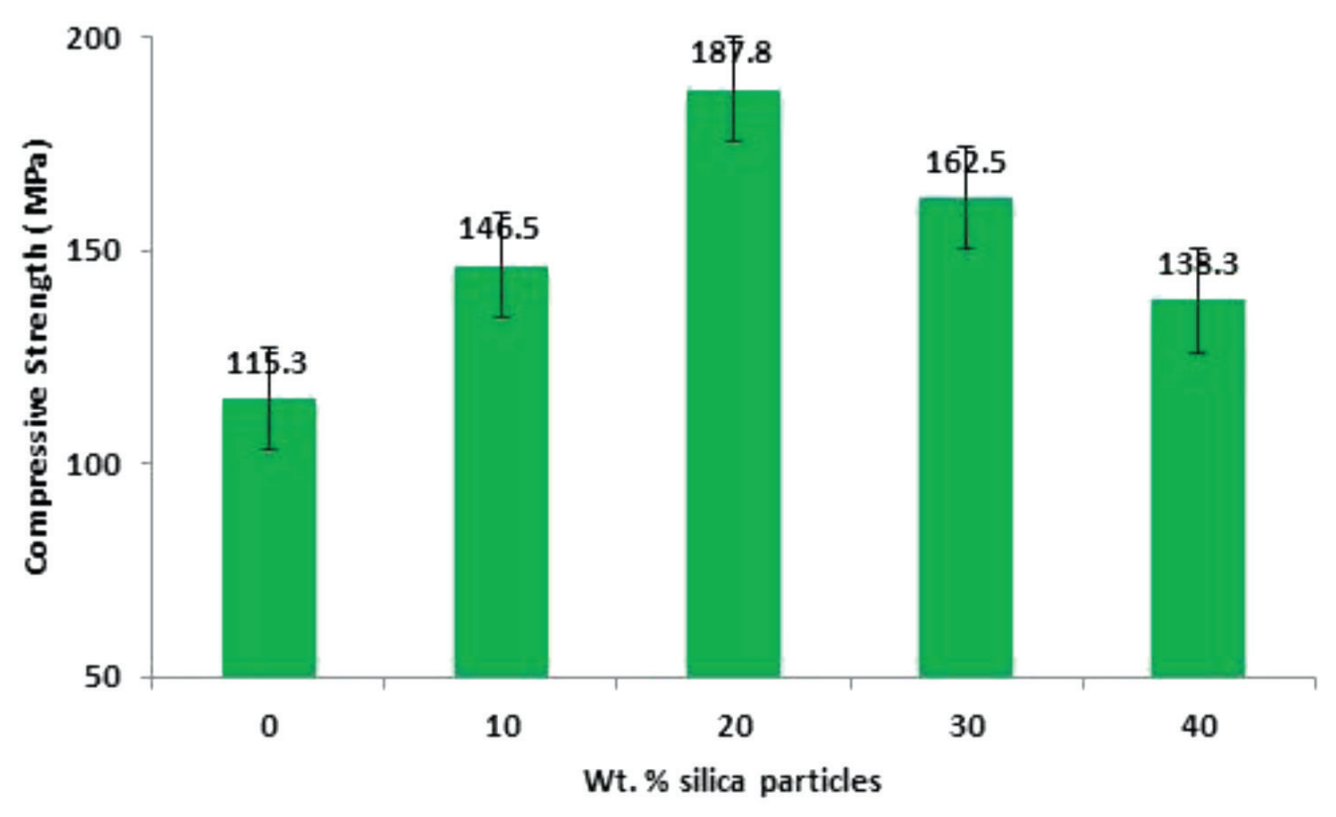

Fig. 6: Variation of compressive strength with silica particles addition

\subsection{Hardness}

The results of hardness property analysis conducted on the carbon composite samples are as presented in Fig. 7. The composites hardness values range from 106.5 to 178.4 Brinell hardness number $(\mathrm{BHN})$ with the unreinforced sample having the lowest value while the peak is exhibited by the sample with 20 wt.\% SP addition. The contribution to a relative high hardness of the reinforced samples may have stemmed from strong cohesion between the carbon matrix and the reinforcement phase that provided effective barrier to dislocation motion.

Silica is reported to be one of the hardest materials as reported by Hassan and Aigbodion [7] and 
Alaneme et al. [1]. However, the low hardness exhibited by the sample with $0 \mathrm{wt} . \%$ SP addition can be attributed to the monolithic and relatively soft carbon matrix. Again, the composite hardness reduces on further SP addition probably due to porosity suggesting that $20 \mathrm{wt}$. \% SP is the optimum required for enhanced hardness characteristic of the carbon composite. However, the composites hardness value being in the range 131.8-178.4 BHN is $54.4 \%$ of the standard hardness put at 270300 BHN for most power plant turbine blades as submitted by Ziegler et al. [12] and Bouville et al. [4].

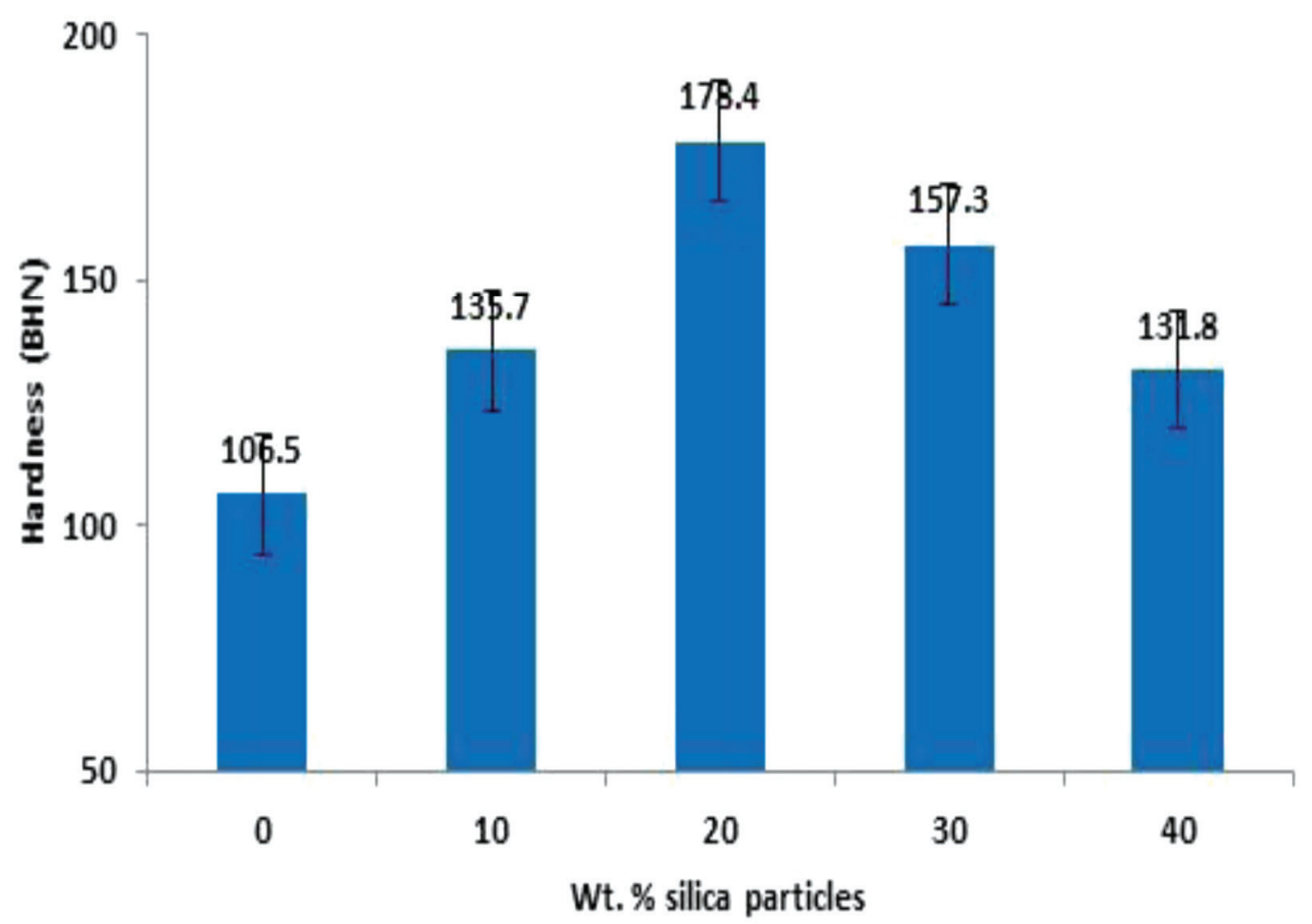

Fig. 7: Variation of hardness with silica particles addition

\subsection{Impact Energy}

Fig. 8 illustrates the amount of energy required to fracture the composites at varied SP additions and is observed to increase progressively from $17.8 \mathrm{~J}$, peaked at $28.7 \mathrm{~J}$, and then dropped monotonously to $19.6 \mathrm{~J}$. The unreinforced sample demonstrated the lowest impact energy which is $17.8 \mathrm{~J}$ while the sample with low carbon/silica particle ratio of $4: 1$ also has relatively low impact energy, 19.6 J. Given these observations, it appears that variations in the level of cohesion between the carbon particles and SP additions influence significantly the impact energy of the composites as an indication of the tough-to-brittle transition behaviour of the composites [5, 11]. This is because, within ratios 8:1 and 5:1 of carbon/silica particle-matching within the system, the composites are conferred with the requisite ability to undergo substantial level of plastic deformation giving rise to impact energy values comparable with standard values of $20 \mathrm{~J}$ (minimum) for steam turbine blades. This is similar to the report of Dowson et al. [6]. 


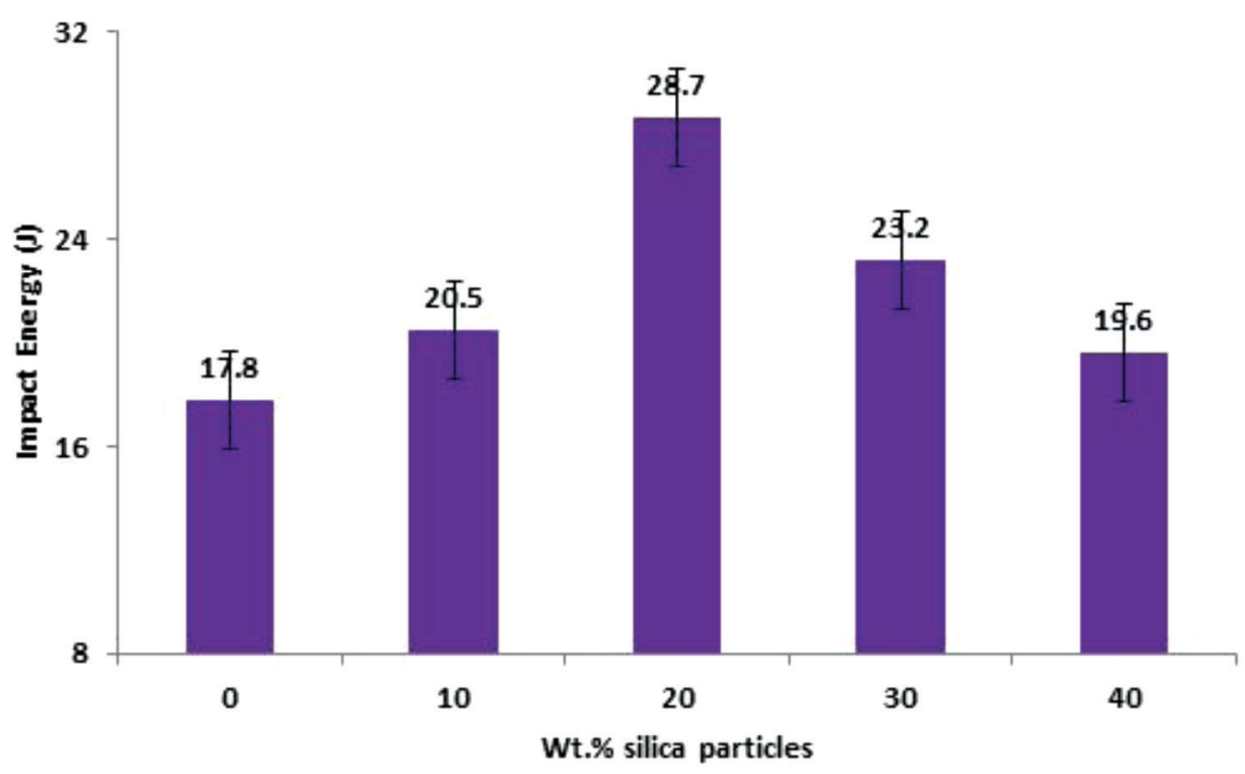

Fig. 8: Variation of impact energy with silica particles addition

\section{Conclusion}

The mechanical characteristics of silica particles reinforced carbon matrix composite have been investigated. The composites best mechanical properties namely: hardness, compressive strength and impact energy were obtained at $20 \mathrm{wt}$. \% silica particles (SP) addition. Hardness of $178.4 \mathrm{BHN}$ exhibited by the composite at $20 \mathrm{wt} . \% \mathrm{SP}$ addition is adjudged sufficient to prevent any surface dysfunction in service. Under compressive loading, the composites ultimate strength performance of $187.8 \mathrm{MPa}$ influenced significantly by matrix-reinforcement ratio are within the values recommended for ceramic composites. At an average of 7:1 of matrix/reinforcement ratio, the composite is conferred with the requisite ability to undergo substantial level of plastic deformation culminating in 28.7 Joules impact energy. The carbon matrix also served as an effective wetting agent which significantly reduces the inherent brittleness of the ceramic composites. In view of the above mechanical performance indices, the ceramic composite produced has a huge potential for application as power plant turbine blade and steam plant bucket.

\section{References}

[1] Alaneme KK, Ademilua AO and Bodunrin MO (2013), Mechanical properties and corrosion behaviour of aluminium hybrid composites reinforced with silicon carbide and bamboo leaf ash, Tribology in Industry, 35: 25-35.

[2] Amirtan G, Kumar A and Balasubramanian M (2011), Thermal conductivity studies on $\mathrm{Si} / \mathrm{SiC}$ ceramic composites, Ceramics International, 37: 423-426.

[3] Bello SA, Agunsoye JO, Adebisi JA, Kolawole FO and Hassan SB (2016), Physical properties of coconut shell nanoparticles, KU Journal of Science, Engineering, and Technology, 12: 63-79.

[4] Bouville F, Marie E and Stevenson A (2015), Strong, tough and stiff bioinspired ceramics from brittle constituents, Cornell University Library, Condensed Matter: Materials Science, 1-27. 
[5] Bristol W and Haley E (2010), Brittleness of materials: implications for composites in relation to impact strength, Journal of Materials Science, $45: 242-250$.

[6] Dowson P, Bauer D and Laney S (2008), Selection of materials and materials related processes for centrifugal compressors and steam turbines in the oil and petrochemical industry, Proceedings of the $3^{\text {th }}$ Turbomachinery Symposium, Houston, TX, USA, 189-209.

[7] Hassan SB and Aigbodion VS (2010), Microstructure and interfacial reaction of Al-Cu-Mg/ bagasse ash particulate composite, Journal of Alloys and Compounds, 491: 571-574.

[8] Madakson PB, Yawas DS and Apasi A (2012), Coconut shell ash characterisation for potential utilisation in metal matrix composite for automotive applications, International Journal of Engineering Science and Technology, 4: 1190 - 1198.

[9] Nadejda P, Emad A, Andreas P and Alfred L (2010), Thermal conductivity of porous SiC composite ceramics derived from paper precursor, Ceramics International, 36: 2203-2207.

[10] Ritchie RO (2011), The conflicts between materials, Natural Materials, 10: 817-822.

[11] Xia Z and Curtin WA (2000), Tough-to-brittle transition in ceramics matrix composite with increasing interfacial shear stress, Acta Materialia, 48: 4879-4892.

[12] Ziegler D, Puccinelli M, Bergallo B and Picasso A (2013), Investigation of turbine blade failure in a thermal power plant case studies, Engineering Failure Analysis, 9 : 192-199. 